\section{CONFIRMACIÓN ETIOLÓGICA DE LOS DOS PRIMEROS CASOS DE HANTAVIROSIS HUMANA EN EL PERÚ}

\section{ETIOLOGIC CONFIRMATION OF THE FIRST TWO CASES OF HUMAN HANTAVIROSIS IN PERU}

\author{
Paquita García ${ }^{1, a}$, Sinti Percy ${ }^{2, b}$, Ana L.Herrera ${ }^{2, c}$, \\ Fernando Donaires ${ }^{1, d}$, Carlos Álvarez ${ }^{3, \mathrm{e}}$, \\ Juan Arrasco ${ }^{4, \mathrm{e}}$, César Cabezas ${ }^{1,5, \mathrm{~d}}$, \\ Hugo Rodríguez ${ }^{3, \mathrm{e}}$, Enrique Mamani ${ }^{1, f}$
}

Sr. Editor. La infección producida por los agentes del género hantavirus produce el síndrome pulmonar por hantavirus (SPH) o la fiebre hemorrágica con síndrome renal (FHSR). La transmisión del virus se produce por contacto directo con secreciones, excrementos o inhalación de material infeccioso en forma de aerosoles provenientes de roedores ${ }^{(1)}$.

En el siglo pasado, dos grandes brotes permitieron descubrir los hantavirus del viejo y nuevo mundo. El primer brote de FHSR, ocurrido durante la Guerra de Korea (1950 a 1953), cuyo agente etiológico fue aislado en 1978 por Lee et al., denominándolo virus Hantaan (HTNV) (2); y el segundo brote de SPH, ocurrido en la región de Four Corners de los EEUU en 1993, identificándose al agente etiológico como virus sin nombre $(\mathrm{SNV})^{(3)}$. En Sudamérica se describió el virus Andes que produce compromiso pulmonar y renal ${ }^{(4)}$.

En el Perú, en abril del 1996, se logró caracterizar una variante del virus Río Mamoré (RIOMV) en un roedor silvestre Oligoryzomys microtis capturado en la ciudad de Iquitos ${ }^{(5)}$ y, en 1998, un estudio de seroprevalencia de anticuerpos IgG, utilizando ELISA para Hantavirus en muestras colectadas de escolares (1993 a 1996), pacientes febriles (1995 a 1996) y roedores (1997) de la ciudad de lquitos, encontró una prevalencia de $2 \%$ (30/1537); $8,2 \%(21 / 257)$ y $3,5 \%(4 / 112)$ respectivamente para el HTNV y SNV ${ }^{(6)}$, lo cual daba indicios de la presencia de la infección por hantavirus en humanos;

\footnotetext{
Instituto Nacional de Salud. Lima, Perú.

Hospital de EsSalud Iquitos. Iquitos, Perú.

Dirección Regional de Salud - Loreto. Loreto, Perú.

Dirección General de Epidemiología. Lima, Perú.

5 Instituto de Medicina Tropical "Daniel A. Carrión”, Universidad Nacional Mayor de San Marcos. Lima, Perú.

a Tecnólogo Médico; ${ }^{\text {b }}$ Médico Neumólogo; ' Médico Intensivista;

${ }^{d}$ Médico Infectólogo; ${ }^{e}$ Médico Epidemiólogo; ${ }^{f}$ Biólogo
}

Recibido: 02-09-11 Aprobado: 14-09-11 sin embargo, hasta el presente año no se había confirmado la enfermedad en humanos.

En el Instituto Nacional de Salud, se recibieron dos muestras de suero provenientes de dos casos fatales con sospecha clínica de SPH y FHSR que ocurrieron entre julio y agosto de 2011 en Loreto, región de la Amazonía peruana. El primer caso correspondió a una mujer de 29 años de edad, natural de lquitos, guía de turismo que visitó localidades ribereñas del río Nanay, quien presentó fiebre, cefalea, edema agudo de pulmón no cardiogénico y falla renal aguda, que requirió de hemodiálisis días antes de su deceso, que ocurrió a los 23 días de su hospitalización.

El segundo caso reportado fue una mujer de 33 años de edad, profesora, procedente del distrito de Punchana, ciudad de lquitos, quien fue internada el 5 de agosto de 2011 en el Hospital de EsSalud Iquitos, a los cinco días de iniciada la enfermedad, presentando fiebre, cefalea, mialgias, manifestaciones hemorrágicas (hemorragia digestiva alta y hematuria), falla renal aguda con compromiso hepático, cardiovascular y daño pulmonar, que conllevó a su muerte a los seis días de su ingreso.

En ambos casos, se determinó la presencia de anticuerpos IgM contra hantavirus mediante la técnica de ELISA IgM de captura. Asimismo, se confirmó el diagnóstico en ambos casos al obtener un producto amplificado de 540 pb para el segmento $M$ del ARN viral utilizando la técnica de RT-PCR NESTED en suero. El análisis de secuenciamiento genético del segmento $\mathrm{M}$ comparativo con las secuencias del Gen Bank, indicaron que el genoma detectado presenta una homología del $97 \%$ con el virus Seoul (AB355731) reportado el 2007 por Troung TT. Las muestras fueron inoculadas en cultivos celulares de la línea VERO y BHK21, encontrándose aún en observación.

Este es el primer reporte de hantavirosis en el Perú, presentados en sus dos formas clínicas: síndrome pulmonar por hantavirus y fiebre hemorrágica con síndrome renal, llamándonos la atención el hallazgo de un hantavirus con alta homología al virus Seoul, variedad que usualmente está asociada con casos urbanos de FHSR (7), cuyo reservorio es el Rattus norvergicus/Rattus rattus, a diferencia del virus sin nombre y el virus Andes que tienen como reservorios a roedores silvestres, Peromyscus maniculatus y Oligorizomys longicaudatus respectivamente. Será importante determinar los reservorios implicados en estos casos, las áreas de riesgo con la fuente de infección y desarrollar el secuenciamiento completo del genoma viral, que incluya el segmento $\mathrm{S}$ y L, para determinar si corresponde al virus Seoul, es una variante genética o pueda ser una nueva especie de hantavirus de la Amazonía peruana. 


\section{AGRADECIMIENTOS}

A la Dra. Silvana Levis del Instituto Nacional de Enfermedades Virales Humanas "Dr. Julio I. Maiztegui”, Pergamino Argentina; a la Dra. Wilma Casanova y a la Blga. Milady Gatti de la Dirección Regional de Salud, por brindarnos las facilidades para realizar las actividades de investigación en relación a los casos; al personal profesional del Laboratorio de Referencia Nacional de Metaxénicas Virales del Instituto Nacional de Salud Susy Merino, Dina Torres, Dana Figueroa, Marco Coaguila, Noelia Milla, por su labor en la investigación laboratorial de los casos presentados.

\section{Fuentes de financiamiento}

Instituto Nacional de Salud. Lima, Perú.

\section{Conflictos de interés}

Los autores declaran no tener conflictos de interés en la publicación de la presente carta.

\section{REFERENCIAS BIBLIOGRÁFICAS}

1. Figueiredo L, Campos G, Rodrigues F. Síndrome pulmonar e cardiovascular por Hantavirus: aspectos epidemiológicos, clínicos, do diagnóstico laboratorial e do tratamento. Rev Soc Bras Med Trop. 2001;34:15-27.

2. Lee HW, Lee PW, Johnson K. Isolation of the etiologic agent of Korean hemorrhagic fever. J Infect Dis. 1978;137:298-308

3. Hjelle B, SW Lee, W Song, Torrez-Martinez N, Song JW, Yanagihara R, et al. Molecular linkage of hantavirus pulmonary syndrome to the white-footed mouse, Peromyscus leucopus: genetic characterization of the $\mathrm{M}$ genome of $\mathrm{New}$ York virus. J Virol. 1995;69:8137-41.

4. OPS. Hantavirus en las Américas: Guía para el diagnóstico, el tratamiento y el control [Internet]. Washington, DC: OPS; 1999 [citado el 15 de agosto de 2011]. Disponible en: http:// www.paho.org/Spanish/AD/DPC/CD/hantavirus-americas. $\mathrm{htm}$.

5. Powers AM, Mercer DR, Watts DM, Guzman H, Fulhorst CF, Popov VL, et al. Isolation and genetic characterization of a Hantavirus (Bunyaviridae: Hantavirus) from a rodent, Oligoryzomys microtis (muridae), collected in northeastern Peru. Am J Trop Med Hyg. 1999;61(1):92-8.

6. Cilloniz C. Evidencia serológica del virus Hantaan, Sin Nombre y Puumala en la región amazónica de lquitos [Tesis para optar el Grado de Magister en Microbiología]. Lima, Perú: Facultad de Medicina, UNMSM; 1998.

7. Kim YS, Ahn C, Han JS, Kim S, Lee JS, Lee PW. Hemorrhagic fever with renal syndrome caused by the Seoul virus. Nephron. 1995;71:419-27.

Correspondencia: María Paquita García Mendoza Dirección: Av. Defensores del Morro 2268, Lima 9, Perú. Teléfono: (511) 617-6200 anexo 1545

Correo electrónico:pgarcia@ins.gob.pe

\section{RETOS PARA LAS NUEVAS REGULACIONES DE PRODUCTOS FARMACÉUTICOS EN EL PERÚ}

\section{CHALLENGES TO NEW REGULATIONS OF PHARMACEUTICAL PRODUCTS IN PERU}

\author{
Hans Vásquez Soplopuco ${ }^{1, a}$, \\ Sofía Salas Pumacayo ${ }^{1, b}$, Linder Figueroa Salvador ${ }^{1, c}$, \\ Sonia Gutierrez Aures ${ }^{1, b}$
}

Sr. Editor. A nivel mundial, la aprobación de medicamentos para comercialización por las autoridades reguladoras nacionales de medicamentos (ARNM), se realiza previa evaluación del balance beneficio riesgo, basado en documentación que sustenta la calidad, eficacia y seguridad ${ }^{(1)}$

Esto no siempre fue así, en Estados Unidos antes de 1938 , no se necesitaba probar la eficacia y seguridad de un medicamento para ser autorizado para su comercialización y, antes de 1962, solo bastaba que un medicamento demuestre seguridad (no eficacia) para ser registrado. Desde 1962 la Administración de Alimentos y Drogas de Estados Unidos (cuyas siglas en inglés son US FDA) empezó a solicitar como requisito para la autorización de comercialización que el medicamento sustente su seguridad y eficacia (por medio de estudios clínicos), A partir de ese año, la US FDA empezó un proceso de revisión de los medicamentos anteriormente aprobados sin evidencia de eficacia ${ }^{(2)}$.

Continuamente la US FDA revisa el balance beneficioriesgo de los medicamentos basándose en datos provenientes de diferentes fuentes y toma decisiones orientadas a proteger la salud de su población, proceso que lo realizan otras ARNM como las del Reino Unido, Francia, Japón y la Agencia Europea de Medicamentos (EMA).

En el Perú, para el registro de los productos farmacéuticos se debía presentar (solamente como sustento de eficacia y seguridad) una declaración jurada para garantizar la eficacia y seguridad de los medicamentos, según estaba estipulado en la Ley General de Salud N. ${ }^{\circ} 26842$ del año 1997; sin embargo, en el 2009 se promulgó la Ley N. ${ }^{\circ} 29459$, la cual establece modificaciones sustanciales en todo el proceso de registro (o autorización de

Dirección de Medicamentos, Insumos y Drogas, Ministerio de Salud. Lima, Perú.

a Médico Cirujano; ${ }^{\text {b }}$ Químico farmacéutico; ${ }^{\text {c }}$ Maestro en Farmacia Clínica 